

Las Naciones Unidas y la CEPAL en el

Cincuentenario de la Organización

Gert Rosenthal

La creación de las Naciones Unidas y de la CEPAL

Hernán Santa Cruz

Derechos humanos: el caso de los niños

Teresa Albánez

Gobernabilidad, competitividad e integración social

Fernando Calderón

Reforma laboral y equidad social:

la privatización de los puertos

Larry A. Burkhalter

Nuevas tendencias en las políticas salariales

Andrés E. Marinakis

Centroamérica: desempefio macroeconómico y

financiamiento social

Francisco Esquivel

Panamá y la integración económica centroamericana

Luis René Caceres

La dualidad del tipo de cambio en la economía cubana de los noventa

Archibald R.M. Ritter

Transnacionalización e integración productiva en

América Latina

Armando Di Filippo

Indice de autores y de temas en la Revista de la CEPAL, números 1 al 57

Orientaciones para los colaboradores de la Revista de la CEPAL 195 


\section{Transnacionalización e integración productiva en América Latina}

\section{Armando Di Filippo}

Asesor Regional en Integración y Cooperación Económica, División de Comercio Intemacional, Transporte y Financiamiento, CEPAL
El comercio entre los países de la ALADI ha crecido con excepcional dinamismo en lo que va corrido de los años noventa, especialmente en la rama de productos metálicos, maquinaria y equipo, en la de productos químicos y en la de productos alimenticios, bebidas y tabaco. Para que este dinamismo se sustente en el largo plazo estos países deberán desarrollar su comercio intraindustrial, promoviendo el abastecimiento reciproco en dichos rubros. En las ramas indicadas se concentra la cuota más importante de capital productivo transnacional en América Latina, y en la đe productos metálicos, maquinaria y equipo es donde más rápidamente aumenta el comercio intraindustrial, y más se nota la vinculación entre el crecimiento del comercio intrarregional y la fuerte presencia de capital transnacional. En la industria automotriz -prototípica de los rasgos señalados- la existencia de regímenes y acuerdos, con fuerte protagonismo empresarial y con elementos preferenciales, ha sido esencial para su supervivencia y crecimiento. Ejemplo de ello son las normas que regulan el intercambio en este rubro entre Argentina y Brasil, y las zonas sometidas al régimen de maquila en México. Al delinear las futuras estrategias de regionalismo abierto y los mecanismos más adecuados para atraer la inversión extranjera directa sin generar una pugna contraproducente entre países, lo observado en el sector automotor sugiere que no sólo con la liberalización económica, sino también con los regímenes especiales acordados entre las empresas involucradas y los miembros de un mismo esquema de integración, se puede atraer y retener el capital productivo transnacional. 
I

\section{Introducción}

Las importaciones recíprocas entre los países de la ALADI, medidas como porcentaje de las importaciones totales de esos países, subieron del 10 al $17 \%$ entre 1990 y 1993. ¿Por qué se produjo este incremento y cuán sustentable puede ser a largo plazo?

Hay indicios cada vez más claros de que estas tendencias derivan de un impacto más que proporcional de la eliminación de las barreras al comercio entre países que, por su relativa cercanía geográfica y su mayor integración física, están teniendo costos de transporte cada vez menores. Podría hablarse de la suma potenciada de dos efectos: el "efecto liberalización" más el "efecto cercanía económica" (Garriga y Sanguinetti, 1994). El impacto sobre el comercio recíproco ha sido aún más fuerte porque los acuerdos de libre comercio suscritos recientemente han acelerado aún más la apertura intrarregional de los países latinoamericanos.

Paralelamente con los acuerdos de libre comercio, sin embargo, han seguido operando regímenes de excepción, entre los que destacan los de la industria automotriz. En el ámbito subregional puede citarse el Protocolo 21 entre Argentina y Brasil y en el hemisférico las zonas procesadoras de exportaciones y el sistema de maquila entre México y Estados Unidos, que siguen vigentes, transitoriamente al menos, aún después de la respectiva incorporación al MERCOSUR y al Tratado de Libre Comercio de Norteamérica (TLCN). Las empresas transnacionales son protagonistas principales de este auge, y están reorganizando su especialización productiva intrarregional e intrahemisférica para capturar las economías de escala y de especialización de los mercados ampliados. Aunque este proceso se beneficia de la liberalización general de los mercados, su impulso principal deriva de las formas administradas y compensadas de comercio que provienen de los regímenes de excepción mencionados.

A la influencia de los elementos estrictamente económicos examinados más arriba, se suma la de otros de más difícil cuantificación, como la afinidad cultural e idiomática, o la distensión política entre países limítrofes que acompañó el retorno a regímenes democráticos en América Latina.

$\square$ Este artículo se basa en Di Filippo, 1994
En cuanto a la sustentabilidad de largo plazo que pueda tener la expansión relativa del intercambio recíproco, al menos en el ámbito estrictamente latinoamericano, dependerá en grado importante de la capacidad de la propia oferta regional para satisfacer el crecimiento de las importaciones latinoamericanas inherente a un proceso de crecimiento sostenido. En otras palabras, de la capacidad de dicha oferta para orientarse hacia rubros manufactureros o de servicios cuya demanda exhibe una alta elasticidad-ingreso.

La potencialidad de crecimiento del mercado regional supera holgadamente a la de los mercados hacia donde se dirige la mayor parte de la oferta regional. La capacidad para crecer de las economías latinoamericanas en el largo plazo es bastante mayor que la de las economías desarrolladas. Sin embargo, en las presentes condiciones de apertura, para que todos los países participantes de un esquema de intercambio puedan apoyarse en las exportaciones recíprocas y estimular este tipo de desarrollo, se necesita una pauta de comercio intraindustrial. A diferencia del comercio interindustrial -característico entre centros y periferias-, el comercio intraindustrial posibilita el crecimiento sostenido del intercambio entre países con niveles de desarrollo y dotaciones relativas de factores más o menos similares, mediante el aprovechamiento de las economías de escala y especialización.

Este papel del comercio intraindustrial en la integración de América Latina y en el fomento de las economías de escala y de especialización no es algo novedoso en las reflexiones de la CEPAL. Hace casi 30 años se afirmaba al respecto: "Las economías de escala de la producción que no pueden aprovecharse por las limitaciones del mercado tienen una magnitud significativa en importantes actividades industriales relacionadas con la producción de bienes duraderos para consumo, bienes de capital y productos intermedios básicos. Esas economías obedecen a varios factores, como la naturaleza indivisible de las inversiones, la falta de proporcionalidad entre el aumento de la capacidad de producción de la planta y el costo de los equipos, y la posibilidad de incorporar tecnologías modernas y cierto grado de especialización cuando se trabaja en altas escalas de producción." "La 
integración regional contribuirá directamente a resolver todos estos problemas del desarrollo que se originan en el tamaño del mercado. En la medida en que se avance en este proceso, las producciones que se radiquen en cada uno de estos países contarán con la demanda potencial de toda el área integrada. Podrán en consecuencia establecerse plantas modernas con dimensiones optimas y con especialización adecuada y será posible continuar la industrialización en aquellas otras ramas que hoy es imposible abordar dentro de los mercados nacionales" (CEPAL, 1965).

Esta visión expresada por la CEPAL a mediados de los años sesenta se ha modificado contemporáneamente en dos sentidos. En primer lugar, la integración económica ya no se está verificando en un proceso de industrialización sustitutiva de las importaciones; lo que pretende hoy es ser compatible con una amplia apertura a la economía mundial y contribuir a ella. En segundo lugar, el comercio intraindustrial ya no se promueve mediante acuerdos sectoriales de complementación económica con fuerte intervención de burocracias gubernamentales en el reparto de las tareas productivas entre países, sino a través del papel cada vez más protagónico de la empresa privada (CEPAL, 1994 a y b). Sin embargo, ya en aquel tiempo el mensaje de la CEPAL implicaba que, el proceso de integración comercial en América Latina, para ser sustentable necesitaba de un crecimiento más que proporcional del comercio recíproco intraindustrial. Hoy esta misma proposición básica -que chocaba contra el principio de las ventajas comparativas estáticas imperante en aquella época- se ve crecientemente confirmada por las orientaciones académicas más recientes (por ejemplo, Krugman y Obstfeld, 1994, cap. 6).

Denominaremos integración productiva de América Latina al establecimiento de una división intrarregional del trabajo que posibilite un desarrollo cada vez más diversificado de la oferta industrial de todos los participantes. La expresión empíricamente verificable del avance de esta integración productiva será el crecimiento del comercio intraindustrial, no sólo entre los propios países latinoamericanos sino también con el resto del mundo.

Este artículo aporta antecedentes respecto del papel protagónico de las empresas transnacionales en la producción de aquellos bienes -fundamentalmente productos metálicos, maquinaria y equipo, y productos químicos- que hoy constituyen el grueso del comercio intraindustrial de los países latinoamericanos.

\section{II}

\section{Las formas de integración productiva}

Hemos caracterizado la integración productiva como el establecimiento de una división intrarregional del trabajo que posibilita un desarrollo cada vez más diversificado de la oferta industrial de todos los países participantes.

Una primera forma de integración productiva es la intraempresarial que se da entre filiales de una misma empresa transnacional. Esta modalidad suele denominarse producción internacional en los estudios sobre empresas transnacionales (UNCTAD, 1993) y se traduce en comercio intrafirma en sentido estricto.

Una segunda forma de la integración productiva es practicada por empresas transnacionales del mundo desarrollado -o sus filiales-, y empresas locales con las cuales ellas subcontratan determinadas operaciones productivas sujetas a especificaciones tecnológicas muy precisas. Surgen aquí diferentes tipos de alianzas y acuerdos que envuelven una estrecha vin- culación "tecnoproductiva" entre las filiales de las empresas transnacionales y los subcontratistas locales, y a los que se ha dado en denominar "nuevas formas de inversion internacional" (Kuwayama, 1992). En la industria automotriz los entrelazamientos derivados de estas alianzas son extremadamente complejos.

Ambas formas examinadas hasta aquí tienen dos rasgos comunes: implican comercio intraindustrial y suelen dan lugar a regímenes especiales de intercambio con exenciones arancelarias totales (como en las zonas francas) o con aranceles que se calculan solamente sobre el valor que se agrega a la parte o componente que será reimportado por el primer exportador (como en el caso de la maquila). Estos tratamientos arancelarios especiales son, por un lado, un reconocimiento de que no se trata de comercio en el sentido clásico ("ricardiano") de la palabra; y por otro lado, implican preferencias recíprocas que son propias de 
los acuerdos de integración o pueden propiciarlos. Asimismo, algunos de los acuerdos sectoriales en vigor incluyen claros componentes de comercio administrado o regulado. Estas modalidades se observan en abundancia entre países desarrollados y en desarrollo, y pueden ser el antecedente de facto de acuerdos de integración, como lo han sido en la inclusión de México en el TLCN. También se dan entre países latinoamericanos, involucrando a filiales de empresas transnacionales y a fabricantes locales de autopartes, como en el convenio relativo a la actividad automotriz entre Argentina y Brasil.

La tercera forma de integración productiva que examinaremos aquí es la que primero apareció. Se trata del proceso de complementación de la oferta dentro de ramas específicas de productos finales, el que da lugar al intercambio de productos pertenecientes a una misma rama o actividad pero con distintas especificaciones. Este tipo de comercio intraindustrial se desarrolló fuertemente, por ejemplo, cuando los países de la actual Unión Europea se especializaron en franjas o nichos productivos muy precisos den- tro de ramas manufactureras más amplias. Todos ellos producían, por ejemplo, maquinaria, electrodomésticos y equipo de transporte, pero de diferentes tipos y calidades. Podían así expandir de manera más equilibrada y dinámica su comercio de manufacturas, aprovechando economías de escala y de especialización. También podían competir con su oferta en el resto del mundo, logrando capturar nichos de mercado complementarios.

Este equilibrado dinamismo no se produjo en otros importantes ejes de comercio en la posguerra. $\mathrm{La}$ CEPAL, en sus estudios iniciales, puso claramente de relieve los desequilibrios del comercio entre regiones centrales y periféricas que intercambiaban productos primarios tradicionales por manufacturas, ante las disparidades de largo plazo en el crecimiento de la demanda de ambos tipos de productos. Tampoco result 6 estructuralmente viable este equilibrio en el intercambio recíproco de economías que eran productoras de bienes primarios tradicionales, porque la falta de diversidad - y de diversificación - de la oferta exportable agotaba rápidamente el dinamismo del intercambio.

\section{III}

\section{La inversión extranjera directa y}

\section{los mercados de destino}

Cuando se intenta vincular la integración con el comportamiento de la inversión extranjera directa (IED), destaca de inmediato el influjo de las empresas transnacionales ya instaladas en la región. Al respecto, estimaciones correspondientes al inicio de los años noventa indican que la IED acumulada en los países miembros de la Asociación Latinoamericana de Integración (ALADI), al valor de libro, alcanzaba en 1990 a 92000 millones de dólares corrientes, en tanto que el flujo ingresado en ese mismo año fue aproximadamente de 7500 millones de dólares corrientes (alrededor de $8 \%$ de la IED acumulada). Un $73 \%$ de esas existencias de capital extranjero correspondía a Brasil y México, porcentaje que llega al $87 \%$ si se le agregan Argentina y Chile.

En esta sección se intenta responder a un conjunto de interrogantes que vinculan la presencia de empresas transnacionales en América Latina con el proceso de integración regional. Las generalizaciones que se formulan están basadas en el análisis de cinco países - Argentina, Brasil, Chile, Colombia y Venezuela-, los que se suponen bastante representativos de las tendencias que se detectan en el seno de la ALADI. La situación de México, país que por carencia de información se excluyó de este examen, reviste características especiales que se analizarán más adelante, en la sección VI.

Cabría formular en este punto algunos interrogantes principales. ¿Cuáles son los sectores productivos en que se concentra la inversión extranjera directa en América Latina? ¿En cuáles de esos sectores el mercado de la ALADI tiene una participación más importante en el total de sus exportaciones? ¿Para cuáles de esos sectores el mercado de la ALADI ha crecido con más rapidez que los mercados extrarregionales?

A estos interrogantes cabría responder que en los países mencionados, con la excepción de Chile, la mitad o más de la inversión extranjera directa se lo- 
caliza en las ramas manufactureras, y dentro de ellas en las de productos metálicos, maquinaria y equipo (división 38 de la CIIU) ${ }^{1}$ y en las de productos químicos (división 35 de la CIUU). La expansión más rápida del mercado de la ALADI para estas ramas acrecienta el interés de las empresas transnacionales por aumentar su oferta en esa dirección. Ambas ramas han albergado inversiones transnacionales vinculadas desde hace décadas a los mercados nacionales de varios de estos países; actualmente se están reestructurando para aprovechar la escala supranacional de los mercados que surgen al amparo de los acuerdos de integración suscritos en los años noventa.

Otra rama manufacturera que merece ser mencionada es la de productos alimenticios, bebidas y tabaco (división 31 de la CIIU). Aunque en proporciones más reducidas, también absorbe un porcentaje no despreciable de la IED manufacturera. Asimismo, informaciones periodísticas recientes dan cuenta de una mayor presencia de las grandes empresas transnacionales en esta actividad. La proporción de las exportaciones en este rubro que es absorbida por la ALADI - salvo en el caso de Colombia- no supera el $20 \%$, pero la cuota que capta el mercado regional está creciendo con más rapidez que las exportaciones totales del rubro.

El peso de estas tres ramas (divisiones 31, 35 y 38 de la cIIU) en el valor de las exportaciones manufactureras difiere mucho de un país a otro.

En Venezuela, tales ramas generan el $78 \%$ de las exportaciones manufactureras totales, debido al peso de la industria petroquímica. En Argentina dan cuenta del $70.3 \%$ de las exportaciones de manufacturas, con predominio de los productos alimenticios, bebidas y tabaco. En Brasil originan el $73.1 \%$ de las ventas manufactureras al exterior, con predominio de los productos metálicos, maquinaria y equipo. En Colombia explican el $42.6 \%$ de las exportaciones manufactureras totales, con predominio de los productos químicos. Por último, en Chile sólo dan origen al $21.8 \%$ de las exportaciones de manufacturas, porque su rubro principal corresponde a las industrias metálicas básicas, en las cuales la contribución de la IED es muy pequeña y el destino de los envíos principalmente extrarregional (véase más adelante en cuadro 2).
La atención preferente que merecen las tres ramas señaladas deriva de su gran capacidad para abastecer el mercado interno de los países donde se instalan. Su competitividad actual y futura encuentra un punto de apoyo, primero en los propios mercados nacionales y luego en los mercados supranacionales que emergen de los actuales acuerdos, y desde allí puede proyectarse hacia el mercado hemisférico o el mundial. Su crecimiento, por lo tanto, está fuertemente ligado al ritmo de desarrollo que alcancen los países de la región. Aunque la elasticidad-ingreso de la demanda de alimentos con algún grado de elaboración es más baja que la de las otras dos ramas, si la región experimentara un sostenido crecimiento de su producto, acompañado de una mejoría en la distribución del ingreso, la perspectiva de crecimiento del rubro de productos alimenticios, bebidas y tabaco sería bastante promisoria. Es en las tres ramas señaladas donde radica la príncipal vinculación entre la IED y la integración económica latinoamericana.

Los datos que se examinan más adelante en los cuadros 1 y 2 (compilados a nivel nacional), muestran que, con anticipación a la ola de acuerdos suscritos en los años noventa, ya en el decenio anterior hubo una recuperación importante del comercio intrarregional a partir de 1985, año en que la baja relativa de ese comercio tocó fondo.

Este cambio de dirección de las exportaciones fue particularmente notable en los productos metálicos, maquinaria y equipo, y en los productos químicos, donde la presencia de las empresas transnacionales es preponderante. En los años noventa la formalización de acuerdos otorgó fuerza y estímulo a un proceso que se inició en la segunda mitad de los años ochenta. Los casos de comercio intraindustrial que se examinarán confirman que las empresas transnacionales en parte se anticiparon a la suscripción de tales acuerdos - bilaterales o subregionales de libre comercio-y empezaron antes o paralelamente su propio proceso de integración de hecho. En consecuencia, si en el mercado de la ALADl ya hubo una creciente absorción de estos productos antes de que se generalizara el proceso de apertura, resulta explicable la gran aceleración de ese comercio a partir de las políticas que se están aplicando en los años noventa.
I Naciones Unidas, Clasificación Industrial Internacional Uniforme de todas las actividades económicas (cliu),
Informes Estadísticos, Serie M 4, Rev, 2. 


\section{IV}

\section{Examen de casos nacionales}

En esta sección pasaremos revista a cinco países de América Latina - Argentina, Brasil, Chile, Colombia y Venezuela - para determinar cuáles son las ramas en que se concentra la IED (cuadro 1), cuál es el destino principal de las exportaciones de dichas ramas y cuáles tienen un crecimiento más dinámico en el mercado de la ALADI (cuadro 2).

El análisis se ha efectuado de la siguiente manera. Se han examinado las ramas correspondientes a divisiones de la cilU que absorban más del $5 \%$ de la IED en bienes. En ellas se distinguen dos grandes grupos. De un lado están las ramas manufactureras en las que se concentra la IED manufacturera, las que se orientan en proporción importante al mercado de la ALADI. Se trata de la rama de productos químicos, y de la de productos metálicos, maquinaria y equipo (divisiones 35 y 38 de la cirU). De otro lado, están las restantes ramas primarias o manufactureras, con participación variable de capital extranjero, según el país, y con exportaciones orientadas en gran medida a los mercados extralatinoamericanos. Dentro de este segundo grupo, en el que predominan las actividades con uso intensivo de recursos naturales, existen algunas ramas (por ejemplo, la de productos alimenticios, bebidas y tabaco) que concentran una cuota creciente de IED y están acrecentando su penetración en la ALADI.

\section{ArgentIna (1985-1989)}

Hasta fines de 1993 se carecía en este país de estimaciones más recientes desglosadas por ramas de actividad económica, que pudieran compararse con los datos de exportación. En 1989, el $18.8 \%$ de la IED total en bienes se concentraba en el sector primario. $\mathrm{Si}$ a este porcentaje se agrega el de otras actividades manufactureras que hacen uso intensivo de recursos naturales, se llega al 35\%. El 70.3\% de las exportaciones totales provino de estos rubros. $Y$ de las exportaciones provenientes de ellos alrededor del $70 \%$ tuvo un destino extrarregional.

Las ramas correspondientes a las divisiones 35 y 38 de la CIIU captaron un $49.6 \%$ de la IED total y originaron el $19 \%$ de las exportaciones totales de bienes. El 42 y el $55 \%$ de las exportaciones totales de estas ramas, respectivamente, se dirigieron a la ALADI.
Las exportaciones totales de las ramas de productos químicos y de productos metálicos, maquinaria y equipo, aumentaron en 260 millones de dólares, en tanto que las destinadas a la ALADI subieron en 376 millones de dólares. Del incremento de las exportaciones manufactureras totales de Argentina, un $32 \%$ se debió a las exportaciones de estas dos ramas a la ALADI.

\section{Brasil (1985-1991)}

De la IED total en bienes existente al fin de este período, sólo un magro $4.3 \%$ correspondió al sector primario, lo que pone de relieve que la agricultura de exportación en este país se halla fundamentalmente en manos brasileñas. Si a ese porcentaje sumamos el de algunas manufacturas con uso intensivo de recursos naturales se llega al $23.3 \%$. El porcentaje de las exportaciones totales correspondiente a los mismos rubros fue de $55.3 \%$. El destino extrarregional de estas exportaciones osciló según la rama entre el 79 y el $94 \%$ del total.

La rama de productos químicos y la de productos metálicos, maquinaria y equipo concentraron un $65 \%$ de la IED en bienes. Las exportaciones de estas ramas representaron el $32 \%$ de las exportaciones totales de bienes, tuvieron destinos más diversificados, y sus ventas a la ALADI no fueron especialmente altas.

Sin embargo, en términos de crecimiento de las exportaciones, el mercado de la ALADI ha sido esencial para la expansión de dichas ramas. El incremento neto de las exportaciones totales en los dos rubros señalados fue de 1155 millones de dólares, en tanto que el de las dirigidas a la ALADI fue de 1690 millones de dólares y contrapesó la caída de las exportaciones extrarregionales (Di Filippo, 1994). El incremento de las exportaciones a la ALADI en estos dos rubros no śblo fue 535 millones de dólares mayor que el de las destinadas al mundo, sino que genero $54 \%$ del aumento de las exportaciones manufactureras totales de Brasil al mundo durante el período.

\section{Chile (1985-1990)}

El $78 \%$ de la IED total en bienes se concentró en el sector primario. Dentro de las actividades manufactu- 
CUADRO 1

América Latina (cinco paises): Inversión extranjera directa por paises y sectores

(Millones de dolares corrientes y porcentajes)

\begin{tabular}{lll}
\hline País & Total & $\begin{array}{l}\text { Sector } \\
\text { primario }\end{array}$
\end{tabular}

Productos
alimenticios,

alimenticios,

Textiles
y cueros

Minerales no
metálicos

Industrias

metálicas

Productos
químicos

Productos

metálicos.

tabaco

\section{Argentina (1989)}

IED en bienes

Porcentajes

\% de crecimiento

51636.0

973.3

5502.0

productos

y equipo

(1985-1989)

100.0

18.8

14.3

2001.0
3.8

324.0
0.6

764.0
3.4

2888.0

12003.0

13663.

$\begin{array}{rr}26.4 & 375.9 \\ & 7.3\end{array}$

Brasil (1991)

IED en bienes

Porcentajes

350.0
100.0

(1)

22.5

0.8

5.5

0.9

0.5

1.1

10.6

\% de crecimiento

179.2
4

21082.0

8224.0

8730.0

35.6

21.1

28.0

32.6

3.2

6384.0

31079.0

11.3

79176.0

28.9

98477.0

58.8

47.0

60.7

48.0

36.0

25.0

810.6

Chile (1990)

IED en bienes

Porcentajes

$\%$ de crecimiento

$$
4438.4
$$

34980.0

2094.0

100.0

78.8
233.4

4.7

154.0

1010.0

172.2

233.4

35.6

79.6

106.2

772.0
1.7

15.7

0.2

5

Colombia (1991)

IED en bienes

Porcentajes

$\begin{array}{rr}3289.9 & 1638.6 \\ 100.0 & 49.8\end{array}$

$231.8 \quad 646.0$

(1985-1991)

$$
75.4
$$

119.0

46.3

646.0
1.9

186.8

$30.3 \quad 55.3$

89.7

17.5

24.5

1283.0

28.9
2.9

51.8

0.9

Venezuela (1991)

tED en bienes

Porcentajes

3426.2

1886.0

30.3

55.3

39.1

17.0

6316.0

19.2

4088.0

(-1.6)

27.9

12.4

97.2

$\%$ de crecimiento

$\begin{array}{rrrr}100.0 & 5.5 & 561.8 & 42.8 \\ & & 16.4 & 1.2\end{array}$

$\begin{array}{rr}42.8 & 158.3 \\ 1.2 & 4.6\end{array}$

210.7

$6.1 \quad 313.4$

11960.0

7469.0

$21.7-73.0$

190.5

385.1

106.1

106.3

305.1

240.1

244.7

132.5

272.9

$(-43.7)$

Fuente: Elaboración propia sobre la base de cifras oficiales. 
reras con uso intensivo de recursos naturales, la presencia de las transnacionales es exigua y sólo el rubro de alimentos, bebidas y tabaco captó un porcentaje de la IED aproximado al 5\%. Estos dos rubros (primario + alimentos) totalizaron el $37.4 \%$ de las exportaciones de bienes. En ninguno de los dos las exportaciones a la ALADI superaron el $15 \%$ del total.

La rama manufacturera de exportación más importante fue la de las industrias metálicas básicas, que absorbieron un porcentaje ínfimo de la IED pero originaron más del $60 \%$ de las exportaciones manufactureras. Las exportaciones totales de esta rama se incrementaron en 3230 millones de d6lares, en tanto que las dirigidas a la ALADI se redujeron en 21 millones; la región latinoamericana absorbió menos del 5\% de ellas y no mostró dinamismo.

El mercado de la ALADI creció un poco más para el rubro de productos alimenticios, bebidas y tabaco, que incrementó sus exportaciones totales en $418 \mathrm{mi}$ llones de dólares ( $82 \%$ ), y las dirigidas a la ALADI en 82 millones de dólares ( $216 \%$ ).

Las ramas de productos químicos y las de productos metálicos, maquinaria y equipo tuvieron un comportamiento bastante atípico en relación con los otros casos nacionales analizados. La primera absorbió menos del $6 \%$ de la IED total y la segunda menos del $3 \%$. Aunque no alcanzaron el límite mínimo de $5 \%$ que se adoptó aquí para incluirlas en el análisis, las hemos considerado por su papel estratégico en todo proceso de industrialización. La participación de una y otra rama en las exportaciones totales fue también pequeña ( 4.2 y $1.5 \%$, respectivamente). Aun así, el mercado de la ALADI fue el más importante para estos rubros y absorbió más del $40 \%$ de sus exportaciones.

Vemos así que estas dos ramas pesaron muy poco (menos del 4\%) en el incremento de las exportaciones manufactureras chilenas. (Compárese esta exigua cifra con el $54 \%$ de Brasil, el $32 \%$ de Argentina, e incluso el $16 \%$ de Colombia.) Sin embargo, durante el período la rama de productos químicos elevó sus exportaciones totales en 224 millones de dólares (159\%) y aquéllas a la ALADI en 108 millones de dólares (256\%).

\section{Colombia (1985-1991)}

En este país la IED total en bienes se concentró fuertemente en el sector primario $(50 \%)$. Si a éste se le suman aquellas actividades con uso intensivo de recursos naturales que capten más de 5\% de la IED en bienes, se llega al $62.4 \%$. Las exportaciones provenientes de estas ramas representaron $64 \%$ de las exportaciones totales de bienes.

De las exportaciones del sector propiamente primario la ALADI captó una cuota muy reducida, pero en la de manufacturas con uso intensivo de recursos naturales su participación fue importante.

Las ramas correspondientes a las divisiones $35 \mathrm{y}$ 38 de la CIIU absorbieron $31.6 \%$ de la IED y sus exportaciones representaron el $13.3 \%$ de las exportaciones totales. Para ellas la ALADI constituye un mercado muy importante, que absorbió alrededor del $40 \%$ de sus exportaciones.

El rubro manufacturero de exportación más importante fue el de cueros y textiles, que concentró el $33.4 \%$ de las exportaciones manufacturas totales, pero como sólo captó $2 \%$ de la IED total no se incluyó en las consideraciones del párrafo anterior. El principal mercado para este rubro no fue América Latina, sino la Unión Europea, seguida por Estados Unidos.

La rama de productos químicos colombiana se comportó de manera análoga a las de Argentina y Brasil respecto del destino de sus exportaciones. Los envíos totales al mundo subieron en 115 millones de dólares (19.3\%) y aquéllos a la ALADI en 201 millones de dólares $(269.2 \%)$. En el rubro de productos metáli$\cos$, maquinaria y equipo las exportaciones totales aumentaron $287 \%$, y las dirigidas a la ALADI $218 \%$.

\section{Venezuela (1985-1991)}

En 1991 el sector primario sólo captó el 5.5\% de la IED total. Si se le suma la participación de la IED en ramas manufactureras con uso intensivo de recursos naturales la cifra sube al $37 \%$. Estos rubros en conjunto generaron el $64 \%$ de las exportaciones totales de bienes, y en ninguno de ellos la importancia de la ALADI como mercado de destino superó el $20 \%$ de las exportaciones totales.

En las ramas manufactureras correspondientes a las divisiones 35 y 38 de la CIIU, los productos químicos absorbieron $34.9 \%$ de la IED total, y los productos metálicos, maquinaria y equipo el $21.7 \%$, totalizando $56.6 \%$ de la IED en bienes. El principal destino de las exportaciones de estos dos rubros, a diferencia de los casos anteriores, fue Estados Unidos, país que absorbió el $50.3 \%$ de las exportaciones de productos químicos y el $42.2 \%$ de las de productos metálicos, maquinaria y equipo.

Sin embargo, las tendencias en el crecimiento del mercado de la ALADl para estas ramas fueron si- 
milares a las observadas respecto de Argentina y Brasil. Las exportaciones manufactureras totales de productos químicos se redujeron en 823 millones de dólares, descenso que no pudo ser totalmente contrarrestado por el aumento de las exportaciones a la ALADI, de 209 millones de dólares. Por otro lado, las exportaciones de productos metálicos, maquinaria y equipo crecieron en 88 millones de dólares $(55 \%)$, en tanto que las dirigidas a la ALADI lo hicieron en 44 millo- nes de dolares ( $187 \%$ ), explicando así el $50 \%$ de crecimiento de las exportaciones de este rubro.

Así, aunque su gravitación absoluta y porcentual es reducida, las dos ramas señaladas encontraron un mercado más dinámico en la ALADI que en el resto del mundo. De manera más general, las exportaciones de los rubros en que se concentra la IED total fureron más dinámicas hacia la ALADI que hacia el resto del mundo.

\section{Integración, empresas transnacionales}

\section{y comercio intraindustrial}

Esta sección aporta antecedentes para sostener que el comercio intraindustrial (Grubel y Lloyd, 1975) e intrafirma, especialmente en la rama de productos metálicos, maquinaria y equipo, es uno de los motores principales de la expansión del comercio recíproco entre los países grandes y medianos de Sudamérica. Pero también pone de relieve que, para ser sustentable, este proceso expansivo requiere mecanismos que promuevan y reequilibren dicho comercio. Teniendo en cuenta el papel protagónico de las empresas transnacionales en estas ramas, la utilización de acuerdos sectoriales de complementación economica puede ser un mecanismo fundamental para una expansión sustentable. A continuación se examinan las tendencias del comercio intraindustrial entre pares de países en las ramas que han captado más IED, y el acuerdo sobre la industria automotriz suscrito entre Argentina y Brasil.

\section{El comercio intraindustrial entre Argentina y Brasil}

Un ejemplo de lo dicho puede encontrarse en la evolución reciente del comercio intraindustrial entre Argentina y Brasil (cuadro 3). Este ejemplo tiene gran significación, porque el eje bilateral de comercio entre estos dos países es el más importante de todos los flujos comerciales de la ALADI y, por supuesto, la base de la expansión del MERCOSUR. Las dos ramas manufactureras que mayor proporción de IED absorben son la de productos químicos y la de productos metálicos, maquinaria y equipo. Sin embargo, mientras la primera ha ido disminuyendo su participación en el comercio recíproco total, la segunda la ha incrementado significativamente.
En 1984 la participación de esta última en el intercambio bilateral era de $15 \%$ y en 1991 de $26 \%$; este incremento fue el más rápido observado a ese nivel de desagregación. Esta rama fue también una de las que más elevó su coeficiente de comercio intraindustrial, de 30.9 a $63.2 \%$ entre 1984 y 1990 (Lucángeli, 1992 y 1993; Di Filippo, 1994).

Un coeficiente alto y creciente de comercio intraindustrial es condición necesaria pero no suficiente para una expansion sustentable del comercio recíproco. Así, por ejemplo, en la rama de productos quími$\cos$ el coeficiente de comercio intraindustrial entre Argentina y Brasil pasó de 18.2 a $67 \%$ entre 1984 y 1990 , pero la participación de esa rama en el comercio entre estos países se redujo del 18.7 al $11.7 \%$.

\section{El comercio Intraindustrial entre Colombla y Venezuela}

Tanto en Colombia como en Venezuela, las dos ramas manufactureras en las que más se concentra la IED son la de productos químicos y la de productos metálicos, maquinaria y equipo. El comercio en esas dos ramas entre ambos países constituye la proporción más importante de su comercio bilateral de manufacturas, pero la participación de la primera se ha expandido, mientras la de la segunda ha decrecido.

Vemos así que la participación de la rama de productos metálicos, maquinaria y equipo en el comercio recíproco entre ambos países bajó de 20.1 a $11.3 \%$ entre 1981 y 1988 , pero que su coeficiente de comercio intraindustrial se elevó de 37.9 a $94.2 \%$.

En el mismo lapso, la participación de la rama 
CUADRO 3

Argentina y Brasil: Intercambio comercial recíproco en grupos significativos de productos, 1990a (Miles de dólares corrientes)

\begin{tabular}{|c|c|c|c|c|}
\hline Grup & s de la CUCv/Rev. 2 & Comercio & Comercio & Coeficiente de comercio \\
\hline 511 & Hidrocarburos, n.e.p. & 33358 & 29048 & 871 \\
\hline 512 & Alcoholes, fenoles y sus derivados & 34467 & 23502 & 682 \\
\hline 513 & Acidos carbox. y sus derivados & 19275 & 11028 & 572 \\
\hline 514 & Compuestos de funciones nitrogenadas & 21097 & 15914 & 754 \\
\hline 515 & Compuestos orgánicos-minerales & 20681 & 18508 & 895 \\
\hline 522 & Elementos químicos inorgánicos & 37054 & 14442 & 390 \\
\hline 523 & Otros prod. químicos inorgánicos & 18119 & 7956 & 439 \\
\hline 531 & Materiales tintor, orgánicos y sintéticos & 5669 & 3046 & 537 \\
\hline 582 & Productos de condensación & 11212 & 8792 & 784 \\
\hline 583 & Productos de polimerización & 39930 & 36378 & 911 \\
\hline 591 & Desinfect, insectic y fungicidas & 19464 & 15364 & 789 \\
\hline 598 & Productos químicos diversos, n.e.p. & 15080 & 13478 & 894 \\
\hline 625 & Neumáticos & 19375 & 17396 & 898 \\
\hline 641 & Papel y cartón & 32159 & 27508 & 855 \\
\hline 652 & Tejidos de algodón & 5677 & 1812 & 319 \\
\hline 674 & Planos universales y chapas & 19720 & 13302 & 675 \\
\hline 684 & Aluminio & 9597 & 8678 & 904 \\
\hline 695 & Herramientas de uso manual & 12317 & 4176 & 339 \\
\hline 713 & Motores combustion interna & 37638 & 29346 & 780 \\
\hline 723 & Maquin. y equipo para ingeniería civil & 10222 & 7292 & 713 \\
\hline 728 & Otras maquín. y equipos especiales & 9296 & 4396 & 473 \\
\hline 741 & Equip. de calefac. y refrigeración, n.e.p. & 7075 & 6950 & 982 \\
\hline 742 & Bombas para líquidos & 11444 & 8684 & 759 \\
\hline 743 & Bombas y compresores & 16553 & 16066 & 971 \\
\hline 745 & Otras máquinas y herramientas & 16774 & 12292 & 733 \\
\hline 749 & Partes y accesorios no eléctricos & 16120 & 11762 & 730 \\
\hline 752 & Equipos de computación & 10961 & 8624 & 787 \\
\hline 772 & Ap. eléctr. para circuitos eléctricos & 5161 & 2516 & 488 \\
\hline 775 & Aparatos de uso doméstico & 5849 & 4984 & 852 \\
\hline 778 & Máquin.y aparatos eléctricos, n.e.p. & 14467 & 11468 & 793 \\
\hline 784 & Autopartes & 96297 & 90286 & 938 \\
\hline 882 & Mat. fotográfico y cinematográfico & 16952 & 6472 & 382 \\
\hline
\end{tabular}

Fuente: Lucángeli, 1992

a Estos grupos significativos corresponden a los gnupos (tres digitos) de la cuct que registraron un coeficiente de comercio intraindustrial superior a 30 y un comercio total superior a cinco millones de dólares.

de productos químicos, por su parte, subió de 21.2 a $48.6 \%$, y el índice de comercio intraindustrial pasó de 61.1 a 90.3 (Fuentes y Jaramillo, 1993).

\section{El comercio intraindustrial entre Méxlco y Colombla}

El comercio entre México y Colombia ha tenido una evolución parecida a la del caso anterior -pero en términos más extremos-. También en Colombia y México las dos ramas manufactureras en las que más se concentró la IED fueron la de productos químicos y la de productos metálicos, maquinaria y equipo.

La participación del comercio recíproco de productos químicos en el total del comercio recíproco manufacturero fue de $41 \%$ en 1981 y de $77 \%$ en 1988 . Los respectivos coeficientes de comercio intraindus- trial fueron de 11.7 y 13.4 , y reflejaron un fuerte desequilibrio comercial en detrimento de Colombia.

A su vez, la participación de la rama de productos metálicos, maquinaria y equipo en el comercio recíproco manufacturero descendió de $25.6 \%$ a $7.1 \%$ en el período mencionado, y los respectivos coeficientes de comercio intraindustrial bajaron en el mismo lapso de 38.4 a $10.4 \%$ (Fuentes y Jaramillo, 1993).

\section{Comercio intraindustrial y acuerdos sectoriales: la industria automotriz en el comercio entre Argentina y Brasil}

El crecimiento del comercio recíproco en una rama puede ir unido a un descenso del coeficiente de comercio intraindustrial, si la balanza bilateral de dicho comercio se desequilibra. En tal caso, la existencia de 
compromisos sectoriales de complementación económica puede servir para encontrar mecanismos de reequilibrio que posibiliten un crecimiento sustentable de largo plazo. Esto parece estar aconteciendo entre Brasil y Argentina en la rama de productos metálicos, maquinaria y equipo (división 38 de la CIIU), con especial referencia a la industria automotriz. La presencia de las empresas transnacionales parece clave en la evolución de este proceso.

A continuación haremos un examen a nivel de tres dígitos de la $\mathrm{CuCl},{ }^{2}$ incluyendo 32 grupos que en 1990 registraron un coeficiente de comercio intraindustrial superior a 30 y un comercio total superior a 5 millones de dólares (cuadro 3). Dichos grupos absorbieron las dos terceras partes del comercio total de manufacturas. En el grupo de autopartes, donde el capital invertido es en gran medida transnacional, el coeficiente de comercio intraindustrial es de 93.8. Otros grupos con altos coeficientes son el de motores de combustión interna y el de neumáticos.

En 1991-1992 estos coeficientes de comercio intraindustrial experimentaron un descenso que puede atribuirse al creciente desequilibrio en el balance del comercio de manufacturas entre Argentina y Brasil. La mayor caída del coeficiente (a la mitad) se verificó en el rubro de productos metálicos, maquinaria y equipo. Esto puede deberse a que en 1990 la activi- dad automotriz registró un comercio total de alrededor de 150 millones de dólares, de los cuales 120 millones constituyeron comercio intraindustrial. En 1991 el comercio en este rubro se triplicó, pero su indice de comercio intraindustrial se redujo a 69 , porque las exportaciones de Brasil hacia Argentina habían crecido mucho más que las inversas.

En 1992 el desequilibrio del complejo automotor se acentuó aún más. El coeficiente alcanzó a 40 , con exportaciones brasileñas por 900 millones de dólares hacia Argentina y 250 millones en la dirección opuesta. Datos más recientes de la misma fuente -anticipados en el periódico El Economista de Buenos Aires el 22 de abril de 1994- señalan una importante tendencia a la recuperación del equilibrio en el comercio entre Argentina y Brasil, lo que ha elevado los índices del comercio intraindustrial. En el intercambio de manufacturas el coeficiente se ubicó en 50 , cifra muy cercana al valor máximo en la serie, alcanzado en 1990. En el complejo automotor pasó de 40 en 1992 a 76 en 1993. Esta recuperación puede atribuirse a dos factores principales. Primero, a la necesidad de dar cumplimiento a compromisos del acuerdo automotor entre ambos países - ejemplo de la importancia equilibrante de los acuerdos sectoriales de complementación económica. Y segundo, a la expansión de la demanda brasileña de automotores (Lucángeli, 1992 y 1993; El Economista, 1994).

\section{VI}

\section{Políticas de promoción orientadas}

\section{a las empresas transnacionales}

De manera general puede afirmarse que la competitividad efectiva de las empresas emana tanto de sus ventajas competitivas propias como de condiciones circundantes de carácter local y nacional provistas por el país en que están localizadas (Porter, 1991; Dunning, 1993).

Es importante distinguir entre estas dos fuentes de competitividad, por su diferente impacto en la formulación de políticas. En efecto, las políticas orientadas a promover la inversión extranjera tenderán a centrarse de preferencia en la creación de ventajas de

2 Naciones Unidas, Clasificación Uniforme del Comercio Internacional, Informes Estadísticos, Serie M. N³4/Rev. 2. localización, en tanto que las políticas orientadas a promover la internacionalización de las empresas locales deberán abordar la creación tanto de ventajas de localización como de ventajas específicas de las propias empresas.

En suma, la competitividad efectiva de una empresa dependerá de sus ventajas competitivas específicas o "ventajas de propiedad"(Dunning, 1993) y de las "ventajas de localización" derivadas del lugar donde se asienta. Cuando una empresa transnacional decide ubicarse en un país anfitrión dado, aporta sus ventajas de propiedad y espera recibir del país las ventajas de localizacion. Por su parte, los países deben descubrir o construir ventajas de localización pro- 
pias que los conviertan en apetecibles para aquellas empresas a las que, de manera selectiva, pretenden atraer. En este caso los mecanismos de selectividad, más que establecer restricciones sectoriales para los capitales menos deseables, buscarían establecer ventajas de localización especialmente diseñadas para atraer los rubros más deseables.

\section{Las zonas procesadoras de exportaciones}

La manera más frontal en que los gobiemos de los países en desarrollo han intentado crear ventajas de localización es a través de la instauración de zonas procesadoras de exportaciones. Con tal objeto, en un ámbito geográficamente delimitado - al que se confiere el carácter de extraterritorial respecto del resto del país - se procede a crear ventajas de localización para empresas manufactureras o ensambladoras orientadas a la exportación. Suelen incluirse instalaciones y edificios que se ofrecen en venta o en arriendo con opción de compra (leasing) a las empresas interesadas. El conjunto de incentivos especiales para dichas empresas incluye exenciones arancelarias y tributarias; eliminación de controles cambiarios; exención, automatización o aceleración de todo tipo de gestiones o tramitaciones gubernamentales, incluyendo el otorgamiento de visas a los ejecutivos y gerentes de nacionalidad extranjera; flexibilidad -0 normativas diferentes- en la aplicación de leyes laborales; autorización para establecer fírmas con $100 \%$ de capital extranjero; disponibilidad de infraestructura física, energética y comunicacional con estándares superiores o especializados para ciertos fines productivos, etc.

Alrededor del $75 \%$ de las zonas de procesamiento de exportaciones que existen en el mundo se dedican a la fabricación de textiles, vestuario y productos electrónicos. Estas actividades se hallan entre las más dinámicas del comercio mundial.

Las ramas productivas que se instalan van siendo de mayor contenido tecnológico a medida que las zonas procesadoras de exportaciones se van afianzando. Ultimamente algunas de estas zonas han estado mejorando su infraestructura de telecomunicaciones para crearse ventajas de localización en actividades de procesamiento de datos, de programas computacionales (Jamaica, la República Dominicana y Costa Rica) o incluso de instalaciones para investigación y desarrollo (Taiwán, provincia de China, Singapur y la República de Corea).

A pesar de que en la mayoría de los países de la ALADI estas modalidades no han prosperado mucho, sí lo han hecho de manera espectacular en México, Centroamérica y el Caribe, donde son una realidad económica de peso creciente. En México, el país de la ALADI en el cual las zonas procesadoras de exportaciones han adquirido mayor gravitación, las actividades de maquila que han prosperado gracias al régimen arancelario preferencial concedido por Estados Unidos generan $41 \%$ de las exportaciones totales. Esta proporción es de $30 \%$ en Jamaica y de $68 \%$ en la República Dominicana.

La instalación de dichas zonas, en sentido estricto, supone la creación de un enclave extraterritorial que en principio puede beneficiar al país anfitrión a través de la generación de divisas, la creación directa de empleos, la incorporación de capital extranjero y de tecnología avanzada, o la capacitación de mano de obra local. Sin embargo, la creación de vínculos entre la zona procesadora de exportaciones y el resto de la economía nacional se frustra en alto grado por la escasa o nula capacidad de difundir estas actividades al resto del país.

Es evidente que esta modalidad de promoción de la IED, aunque contribuya a la globalización y apertura e incluso a fomentar preferencias hemisféricas (como en la relación de México con Estados Unidos), difícilmente permite extender sus beneficios al resto del territorio nacional, y mucho menos promover la integracion regional entre las restantes economías de la ALADI.

Las empresas transnacionales prefieren localizarse en las zonas procesadoras de exportaciones cuando éstas les ofrecen dos tipos de ventajas de localización. Primero, costos más bajos en mano de obra, energía u otros factores o insumos; y segundo, cercanía a un centro de consumo importante, lo que reduce los fletes para acceder a él y aumenta por esa vía la competitividad. Cuando las empresas localizadas en la zona procesadora de exportaciones gozan de preferencias arancelarias para penetrar en el gran mercado de destino - como en el caso del régimen de maquila concedido a México por los Estados Unidos - las ventajas de localización se acrecientan enormemente para las empresas que allí se instalan. Sin embargo, el objetivo de esas empresas no es el de integrarse de manera sistémica al tejido productivo del país anfitrión, puesto que prefieren la situación excepcional de extraterritorialidad. Sólo tratan de aprovechar ventajas muy específicas de localización, en el marco de estrategias dirigidas a maximizar la rentabilidad dentro de sus propias cadenas de valor agregado. 
En América Latina y el Caribe, la importancia de las zonas procesadoras de exportaciones se manifiesta a nivel hemisférico en el seno del TLCN, al que ya pertenece México, o dentro de los regímenes preferenciales de comercio que Estados Unidos ha establecido con países de Centroamérica y el Caribe. Estos atreglos comerciales de carácter preferencial merecen dos comentarios. Primero, implican un significativo componente de comercio administrado, negociado previamente con las empresas transnacionales y orientado a promover el intercambio intraindustrial; y segundo, plantean algunos interrogantes respecto de los beneficios de los acuerdos para las empresas locales que participan. Ambas observaciones pueden ilustrarse con el funcionamiento de las actividades de maquila en la industria automotriz mexicana.

Desde fines de 1989, las autoridades mexicanas han eliminado todas las restricciones a la importación para la industria de autopartes; pero para que los fabricantes de automóviles puedan importar vehículos terminados deben exportar vehículos o componentes por un valor equivalente. Como se ve, esta disposición favorece de manera directa el crecimiento del comercio intraindustrial y, en esta rama, especialmente del comercio intrafirma. En 1991 se permitió que las empresas armadoras importen vehículos nuevos siempre y cuando demuestren tener un excedente en su comercio internacional; con esto se introdujo un mecanismo difícilmente compatible con las cláusulas de la Ronda Uruguay respecto de las inversiones ligadas al comercio. Sin embargo, la posición de las empresas transnacionales se fortaleció, al permitirse la participación de $100 \%$ de capital extranjero en las empresas de autopartes.

Hasta aquí algunas muestras del carácter administrado de los convenios automotrices entre México y Estados Unidos. Sin embargo gracias a estas regulaciones directas el indice de comercio intraindustrial de las industrias de autopartes y automovilísticas, consideradas como un solo sector, se ha hecho extremadamente elevado. Con la firma del TLCN no se ha producido la liberalización del sector, sino que se ha prorrogado la vigencia de estos acuerdos por casi una década.

Las empresas mexicanas de autopartes involucradas en este proceso manifiestan algunas inquietudes. En primer lugar, ven obstaculizada la búsqueda de nuevos mercados de exportación, pues los acuerdos celebrados las obligan a expottar por intermedio del socio transnacional que provee la tecnología. En segundo lugar, a medida que el TLCN entre plenamente en vigencia, abre la posibilidad de que los propietarios de la tecnología prefieran producir en Estados Unidos - -por ejemplo, debido a presiones sindicales internas u otras causas-y exportar directamente a México, liquidando a las empresas mexicanas de autopartes que dependen totalmente de aquella tecnología. En tercer lugar, temen la competencia de las propias empresas transnacionales estadounidenses: General Motors posee 26 plantas maquiladoras en México y prevé abrir otras (Mattar y Schatan, 1993, p. 111 y siguientes).

En los restantes países de la ALADI -es decir, los países de América del Sur- la existencia de zonas procesadoras de exportaciones podría tener un efecto contraproducente para el avance de los esquemas subregionales de integración. Aun admitiendo que los productos provenientes de tales zonas sean considerados como externos al MERCosur o el Grupo Andino, su cercanía geográfica a éstos aumenta su competitividad, por la reducción de los costos de transporte de las empresas allí localizadas que "exportan" al interior de dichas áreas. El objetivo fundamental de esquemas como el MERCOSUR o el Grupo Andino debe ser el de compatibilizar y armonizar los regímenes de sus miembros respecto de la inversión extranjera, para que las empresas se localicen e involucren dentro de los mercados ampliados. De ese modo los países anfitriones pueden aprovechar plenamente todas las externalidades que derivan de esta instalación, objetivo que se frustra parcialmente cuando las empresas optan por instalar sus plantas en el "borde" de ellos, para acrecentar la competitividad comercial de sus exportaciones hacia mercados que, gracias a los procesos integradores, aumentan su tamaño y dinamismo.

Para evitar que el recurrir a la instalación de zonas de procesamientos de exportaciones sea una tentación demasiado fuerte para los países con menos desarrollo industrial dentro de ciertos esquemas subregionales, es preciso que en ellos los miembros más desarrollados creen y tomen medidas que apoyen la participación de todos en un desarrollo industrial integrado que se asiente en el comercio intraindustrial (Paes Saboia, 1993). Este apoyo podría manifestarse a través de la cooperación en infraestructura o parques industriales que permitan crear algunas ventajas de localización, y de acuerdos sectoriales de complementación económica que propicien, entre otras cosas, la capacitación técnica y el respaldo financiero.

\section{Regímenes especiales. El sector automotriz en Argentina}

Por oposición a las experiencias analizadas más atrás, 
que presentan una proyección hemisférica, en el cono sur de América Latina las empresas transnacionales están contribuyendo de manera decisiva a la expansión del comercio intrarregional.

Dentro del MERCOSUR, entre las actividades con fuerte participación de las empresas transnacionales, la industria automotriz de Argentina y Brasil está sujeta también a un acuerdo establecido en el Protocolo 21. Antes de examinarlo conviene hacer referencia al régimen para la actividad automotriz vigente en Argentina y directamente ligado a dicho acuerdo.

A partir de 1991 y con vigencia hasta 1994, se estableció en Argentina un régimen automotor que rige para las empresas transnacionales que operan en este sector, algunas de ellas asociadas a capitales nacionales. Dicho régimen estipula, entre otras, las normas siguientes: i) proporciones determinadas de contenido importado para los productos elaborados en el país; ii) obligaciones de intercambio compensado, con programas anuales o plurianuales, y iii) contenidos mínimos obligatorios de los productos del sector de autopartes, con independencia de las exportaciones anuales de las empresas terminales.

Estas normas guardan correspondencia con otras del acuerdo automotor entre Brasil y Argentina (Protocolo 21), en el que el comercio bilateral se regula sobre la base de programas integrados por empresas, estableciendo cupos de intercambio para vehículos y autopartes y exceptuando a este comercio del pago de aranceles. El objetivo es lograr en esta actividad el equilibrio del comercio recíproco y la complementación productiva, es decir, la expansión del comercio intraindustrial dentro del sector.

Al igual que en la relación entre México y Estados Unidos, las normas anteriores tampoco parecen ser compatibles con los acuerdos recientes de la Ronda Uruguay del GATT sobre medidas en materia de inversiones relacionadas con el comercio. Dichos acuerdos estipulan el trato nacional del inversionista extranjero, y la eliminación general de toda restricción cuantitativa al comercio, como la obligación de exportar una cuota de lo producido o de usar insumos nacionales.

En relación con el régimen para la actividad automotriz, un estudio reciente sobre este sector desde el punto de vista de la economía argentina (Chudnosky, López y Porta, 1994, pp. 37 a 39) expresa lo siguiente: "El desemper̂́o exportador de la industria automotriz es consecuencia del esquema regulatorio sectorial en vigencia desde 1991. Para las terminales, el estímulo para seguir produciendo pasa por mantener su posición de liderazgo en el mercado argentino. En efecto, hay consenso en señalar que, de haberse liberalizado totalmente las importaciones del sector, la producción local de vehículos terminados habria prácticamente desaparecido (o hubiera subsistido como actividad de armaduría). En esas circunstancias, es probable que buena parte del mercado que hoy abastecen las terminales aquí instaladas fuera absorbida por otros productores, especialmente de origen asiático. Si bien se trata de empresas con redes globales de comercio, que podrían abastecer el mercado argentino con automóviles provenientes de otras filiales fabricados a costos inferiores, los mayores costos de la producción local son más que compensados por una cuota de mercado superior al que tendrían en un escenario de abastecimiento basado en importaciones. Esta evaluación se refuerza al considerar que dos de las terminales son controladas por socios argentinos, impedidos obviamente de abastecer el mercado local desde otras localizaciones. De hecho, el régimen sectorial no sólo logró la permanencia de las terminales ya instaladas, sino que además estimuló el retomo de una terminal estadounidense que se había retirado a fines de los años setenta y generó interés en algunas automotrices japonesas que han anunciado planes de radicación".

$\mathrm{Y}$ respecto del impacto de la existencia del MERCOSUR en este régimen, el mismo estudio señala: "Es importante remarcar que el MERCOSUR es funcional para esta industria en la Argentina sólo en tanto subsista un régimen especial de intercambio administrado; en otras palabras, no es el programa general de desgravaciones arancelarias para el comercio intrazona el factor clave, sino el esquema sectorial que regula el intercambio entre Argentina y Brasil".

Se trata, entonces, de lograr un razonable equilibrio entre el respeto a las normas más recientes de la Ronda Uruguay sobre las inversiones vinculadas al comercio, y los mecanismos de polf́tica industrial que han demostrado ser decisivos para impulsar el comercio entre los países de la ALADI. La idea no es, evidentemente, mantener un proteccionismo recalcitrante a la vieja usanza, sino evitar un aperturismo prematuro que impida que las empresas instaladas recuperen su competitividad y resulte letal para ramas industriales tan importante como la de nuestro ejemplo. 


\section{VII}

\section{Recapitulación}

A modo de breve recapitulación de algunas de las comprobaciones básicas de este trabajo, diremos que el comercio entre los países de la ALADI ha crecido con excepcional dinamismo en lo que va corrido de los años noventa. Este mayor dinamismo comenzó a observarse ya en el segundo quinquenio de los años ochenta, y se manifest 6 en una elevación gradual de la participación de la ALADI en las exportaciones de los países que integran este esquema. Las ramas más dinámicas han sido la de productos metálicos, maquinaria y equipo (división 38 de la ciIU), la de productos químicos (división 35 de la ciUu), y la de productos alimenticios, bebidas y tabaco (división 31 de la CIIU).

En estas mismas ramas se concentra también el capital productivo transnacional en América Latina. De estas tres, sin embargo, es en la de productos metálicos, maquinaria y equipo -y especialmente en el complejo automotor- donde más claramente se nota la vinculación del crecimiento del comercio entre los países de la ALADI con la fuerte presencia del capital transnacional. Otro tanto ha acontecido en el caso de México, pero en relación al comercio intrahemisférico, en lo que respecta a la estructura de sus exportaciones hacia Estados Unidos.

En la industria automotriz, que es prototípica de los rasgos descritos más atrás, es visible la presencia de regímenes y acuerdos que apuntan mucho más allá de una mera liberalización del intercambio, y que poseen un alto componente de comercio preferencial que llega a los límites —o quizás los sobrepasa- de las normas multilaterales admitidas en el GATT. En efecto, estos regímenes no se limitan a una mera apertura recíproca más intensa que la apertura global, sino que incluyen formas explícitas de protección a la actividad de las empresas transnacionales y a las corrientes de intercambio reguladas por los acuerdos: por ejemplo, al exigir cierto equilibrio en las balanzas comerciales de las empresas protegidas por los acuerdos como una condición para el equilibrio de los flujos recíprocos que determinan la existencia de comercio intraindustrial.

Estos rasgos son visibles tanto en el régimen establecido para la industria automotriz entre Argentina y Brasil, como en las zonas francas de México sometidas al régimen de maquila. En este segundo caso se generan políticas comerciales, industriales y fiscales ad hoc en el área declarada extraterritorial en que se asienta la zona procesadora de exportaciones.

Estos mecanismos se han manifestado adecuados para promover el comercio tanto intrahemisférico como intrarregional, con flujos que, por la alta elasticidad ingreso de su demanda y el carácter intraindustrial de su producción e intercambio, pueden ser sustentables en el largo plazo.

Un tema central en las futuras estrategias de regionalismo abierto será el de identificar los mecanismos más idóneos para atraer la IED sin generar entre países miembros de un mismo esquema integrador una pugna que termine perjudicando los intereses de cada uno. Los antecedentes recogidos en el sector automotor sugieren que no fue sólo a través de la liberalización económica, sino también mediante los regímenes especiales convenidos entre las empresas involucradas y los miembros de un mismo esquema de integración, que se ha logrado atraer y retener al capital productivo transnacional.

\section{Bibliografia}

CEPAL (Comisión Económica para América Latina y el Caribe) (1965): Contribución a la política de integración económica de America Latina. E/CN.12/728, Santiago de Chile.

(1993a): América Latima: comercio exterior según la clasificacion industrial internacional uniforme de todas las actividades económicas (CIU): Exportaciones, Cuadernos Estadísticos de la CEPAL, N'19, vol. I, LC/G.1754-P, Santiago de Chile.

(1993b): Directorio sobre inversión extranjera en Améri. ca Latina y el Caribe 1993: marco legal e información estadistica, LC/R.1325, Santiago de Chile. (1994a): El regionalismo abierto en América Latina y el Caribe: la integración economica al servicio de la transfor. mación productiva con equidad, LC/G.1801(SES.25/4), Santiago de Chile.

(1994b): América Latina y El Caribe: políticas para mejorar la inserción en la economía mundial. LC/G.1800 (SES.25/3), Santiago de Chile.

Chudnovsky, D., A. Lopez y F. Porta (1994): La nueva inversion extranjera directa en la Argentina. Privatizaciones, mercado interno e integración regional. Documentos de trabajo, 
$N^{\circ} 15$, Buenos Aires, Centro de investigaciones para ta transformación (CENTT).

Di Filippo, A. (1994): Regionalismo abierto e inversión extranjera en América Latina, Documentos de trabajo, $\mathrm{N}^{\circ} 34$, Santiago de Chile, CEPAL.

Dunning, J. H. (ed) (1993): Trade, location of economic activity and the multinational enterprise: $A$ search for an eclectic approach. Extraído de The Theory of Transnational Corporations, vol. I, Londres, The United Nations Library on transnational corporations.

El Economista (1994): Año XLIV, $\mathbf{N}^{\circ} 2306$, Buenos Aires, 22 de abril.

Fuentes, A. y H. Jaramillo (1993): El comercio intraindustrial para La especialización de América Latina, serie Documentos CLADEI-FESCOL, $\mathrm{N}^{\circ} 4$, Santa Fe de Bogotá, Corporación Latinoamericana de Economía Internacional (CLADEi)/Fundación Friedrich Ebert (FESCOL).

Garriga, M. y P. Sanguinetti (1994): ¿Es el MERCOSUR un bloque natural?, Buenos Aires, Centro de Economía Internacional, Ministerio de Relaciones Exteriores y Culto.

Grubel, H. G. y P. J. Lloyd (1975): Intra-industry Trade: The theory and Measurement of International Trade in Differenciated Products, Nueva York, John Wiley \& Sons.

Kuwayama, M. (1992): New forms of investment (NFI) in Latin American-United States trade relations. CEPAL, Working Paper $\mathrm{N}^{\circ} 7$. Santiago de Chile, CEPAL, septiembre.
Krugman, P. y M. Obstfeld (1994): Economia Inemacional, España, McGraw-Hill, segunda Edición.

Lucángeli, J. (1992): Integración comercial, intercambio intraindustrial y creación y desvío de comercio, Buenos Aires, Proyecto Integración Económica de la Subsecretaría de Estudios Económicos de la Secretaría de Programación Económica, mimeo.

(1993): La presencia del comercio intraindustrial en el intercambio entre la Argentina y Brasil, Boletín Informativo Techint, $\mathrm{N}^{\circ} 275$, Buenos Aires, Techint, julio-septiembre.

Mattar, J. y C. Schatan (1993): El comercio intraindustrial e ìntrafirma México-Estados Unidos. Autopartes, electrónicos y petroquímicos, Comercio Exterior, vol. $43, \mathrm{~N}^{\circ} 2$, México, D.F., Banco Nacional de Comercio Exterior, S.N.C., 2 de febrero.

Paes Saboia, E. (1993); As zonas francas e o Mercosul, Boletim de Integraçäo Latino-Americana, $\mathrm{N}^{\circ}$ 9, Brasilia, Ministerio de Relaciones Exteriores, abril-junio.

Porter, M. E. (1991): La ventaja competitiva de las naciones, Buenos Aires, Javier Vergara Editor S.A.

UNCTAD (Conferencia de las Naciones Unidas sobre Comercio y Desarrotlo (1993): Transnational Corporations and Integrated International Production. World Investment Report, Nueva York. Publicación de las Naciones Unidas, $\mathrm{N}^{\circ}$ de venta E.93.1I.A. 14. 